Published as: Afonso Macheca, Dhorali Gnanasekaran, Walter W. Focke. Surfactant-free dimer fatty acid polyamide/montmorillonite bio-nanocomposites. Colloid and Polymer Science: 292(3) (2014) 669-676 DOI: 10.1007/s00396-013-3122-7. http://link.springer.com/article/10.1007\%2Fs00396-013-3122-7

\title{
Surfactant-free dimer fatty acid polyamide/montmorillonite bio-nanocomposites
}

Afonso Macheca, Dhorali Gnanasekaran, Walter W. Focke*

Institute of Applied Materials, Department of Chemical Engineering, University of Pretoria, Phone: (+27) 12420 3728, Fax: (+27) 12420 2516, Pretoria 0002, South Africa

\begin{abstract}
Polyamide bio-nanocomposites were successfully prepared using a surfactant-free approach. The clay morphology was fixed by dispersing the ammonium ion-exchanged clay in acetic acid. This was mixed with an acetic acid solution of the polyamide and the composite was recovered by precipitation with water. The composites featured a mixed morphology containing some exfoliated clay sheets together with nano-sized clay tactoids. Bio-nanocomposites containing as much as $27.5 \mathrm{wt}$ \% clay were obtained. At this filler level, and depending on the temperature, the modulus was up to nine times higher than that of the parent polymer. Addition of clay also increased the glass transition temperature by as much as $5{ }^{\circ} \mathrm{C}$. This indicates that the high interfacial surface area, presented by the clay platelets dispersed in the matrix, significantly impaired the polymer chain mobility.
\end{abstract}

Keywords: Nano composites; Solution intercalation; Thermomechanical properties

\footnotetext{
*Corresponding author. Tel.: +27 (0)83 3266549

E-mail address: walter.focke@up.ac.za (W.W. Focke)
} 


\section{Introduction}

Biopolymers originate from renewable resources such as plant oils and agro-industrial waste [1-6]. Compared to equivalent petroleum-based polymers, biopolymers often feature relatively poor mechanical, physical and processing properties. These drawbacks plus higher costs make them less competitive and limits their use in most applications [7]. Addition of inorganic fillers can significantly contribute towards improving biopolymer properties allowing them to be used in a variety of applications $[4,8]$.

Reinforcing polymers with inorganic fillers is a common practice in the plastic industry to improve properties and to reduce production costs $[9,10]$. Reinforcing polymers with layered silicate nanoclays can improve stiffness, increase heat resistance, lower gas permeability and decrease flammability [4,11,12]. Aspect ratios (length/thickness) greater than a thousand are possible [13]. Montmorillonite (MMT) is the most commonly used layered silicate. It is a hydrated alumina-silicate layered clay mineral consisting of an edgeshared octahedral sheet of aluminium hydroxide between two silica tetrahedral layers $[9,14]$. Highly favourable polymer-surface interactions are essential for thorough clay sheet dispersion $[15,16]$. Thus it is conventional to organomodify these clays with cationic surfactants to improve compatibility with the polymer matrix and to facilitate delamination and exfoliation [17,9].

Dimer fatty acid-based polyamides are a special class of biopolymers derived from plant oils $[1,18,19]$. Compared to other polyamides, they feature lower water uptake and ease of processing (owing to a lower melt viscosity). Composites based on these materials have been characterized and their properties studied using different approaches [20,3]. However, to our knowledge, the properties of thermoplastic dimer fatty acid polyamide-clay nanocomposites have not yet been reported. 
These bio-based polyamides are of low molecular mass and are soluble in a variety of organic solvents. They have amine end groups that are protonated when these polymers are dissolved in suitable carboxylic acids, e.g. acetic acid. This means that organomodification of the clays should be possible via solution intercalation of the polymer chains per se. Thus it should, at least in principle, be possible to prepare clay nanocomposites without the need for organomodification with surfactants. In addition, the solution route should enable the preparation of nanocomposites with relatively high clay contents [21]. These are the ideas that were explored in the present study. Fig. 1 provides a schematic outline of the conceptual approach that was followed in the present investigation.

\section{Experimental}

Materials

G \& W Base and Industrial Minerals supplied Boane bentonite in purified form as a soda ashactivated dispersion. The $\mathrm{pH}$ of the bentonite slurry was 7.4 and the solids content was 19.2 wt.\%. The cation exchange capacity (CEC) of this clay was $0.70 \mathrm{meq} / \mathrm{g}$. Acetic acid (glacial), ammonium chloride and acetone were obtained from Merck Chemicals and used as received. Euremelt 2138 is an amorphous copolyamide that was supplied by Huntsman. According to the supplier, this grade has a softening point in the range $138{ }^{\circ} \mathrm{C}$ to $148{ }^{\circ} \mathrm{C}$ and an amine value of $\leq 4 \mathrm{mg} \mathrm{KOH} / \mathrm{g}$ polymer.

\section{Sample preparations}

The ammonium exchanged montmorillonite $\left(\mathrm{NH}_{4}{ }^{+}\right.$-MMT) was prepared as follows: $200 \mathrm{~g}$ of the bentonite slurry was suspended in $500 \mathrm{~mL}$ of a $1 \mathrm{M}$ solution of $\mathrm{NH}_{4} \mathrm{Cl}$ at a $\mathrm{pH}=5$. The suspension was agitated on shaker at a speed of approximately $200 \mathrm{rpm}$ at RT for $2 \mathrm{~h}$ and 
centrifuged for $1 \mathrm{~h}$. The supernatant was decanted and replaced with fresh ammonium chloride solution. This procedure was repeated 4 times. The $\mathrm{NH}_{4}{ }^{+}-\mathrm{MMT}$ was washed with a large volume of de-ionized water until all $\mathrm{Cl}^{-}$were removed (checked with $\mathrm{AgNO}_{3}$ solution). The $\mathrm{NH}_{4}{ }^{+}$-MMT clay was then dispersed in glacial acetic acid at a solids content of ca.10 wt.\%. This dispersion was used to prepare the polymer composites. One sample of the clay dispersion in water was washed two more times with de-ionized water and finally with neat acetone. It was allowed to air-dry before drying for $24 \mathrm{~h}$ in a convection oven set at $60{ }^{\circ} \mathrm{C}$. The dried sample was ground into a powder with an aggregate particle size $<75 \mu \mathrm{m}$ for further analysis.

A typical preparation procedure for the polyamide clay composites was as follows. A weighed amount of the polyamide was first dissolved in acetic acid, corresponding to 10 wt. $\%$ of polyamide solution. In an $800 \mathrm{~mL}$ stainless steel container, a predetermined amount of 10 w. $\mathrm{t} \% \mathrm{NH}_{4}{ }^{+}-\mathrm{MMT}$ dispersion in acetic acid was mixed at $\mathrm{RT}$ in a high shear mixer for 2 minutes. Then $10 \mathrm{wt} . \%$ of polyamide solution was added drop by drop. After completion, mixing was continued for another $10 \mathrm{~min}$. Then, de-ionized water was added during the mixing process in order to precipitate the polymer bio-nanocomposites. The precipitate was separated from the solution by decantation. The generated composites corresponded to targeted loads of ca. $7.5 \mathrm{wt} . \%, 15 \mathrm{wt} . \%$ and $30 \mathrm{wt} . \%$ clay. The precipitates were washed with de-ionized water. They were then immersed in a large amount of de-ionized water for six days. The de-ionized water was replaced with fresh water on a daily basis. Following these steps the composites were allowed to dry at ambient conditions. Finally, they were dried in a convection oven at $60{ }^{\circ} \mathrm{C}$ for $24 \mathrm{~h}$. Neat polyamide polymer was also subjected to the same procedure to prepare the sample used for property comparisons. Finally thin polymer test sheets were made by hot pressing at temperatures between $160{ }^{\circ} \mathrm{C}$ and $180{ }^{\circ} \mathrm{C}$ for 15 minutes. 


\section{Characterization}

Major elemental analysis was executed on fused beads using an ARL9400XP+ XRF spectrometer. X-ray diffraction was conducted on a PANalytical X'Pert Pro powder diffractometer with $\mathrm{X}^{\prime}$ Celerator detector and variable divergence and receiving slits with $\mathrm{Fe}$ filtered Co-K $\alpha$ radiation $(\lambda=0.17901 \mathrm{~nm})$ in the $2 \theta$ range from $2^{\circ}$ to $60^{\circ}$ at a scan rate of $1.0^{\circ}$ $\min ^{-1}$

The surface morphology of polymer composites was examined with a Zeiss Ultra 55 FESEM at $60 \mathrm{kV}$. Thin blocks of sample were cut from the specimens or obtained by fracturing at cryogenic temperatures. Transmission electron microscope (TEM) (JEM$1200 \mathrm{EX}$, JEOL, Tokyo, Japan) (acceleration voltage $100 \mathrm{kV}$ ) was used to study the morphological structure of bio-nanocomposites. The TEM samples were prepared by dispersing the pristine polymer or the nanocomposites in acetic acid $\left(1 \mathrm{~g} \mathrm{~L}^{-1}\right)$ solution before depositing onto a $3 \mathrm{~mm}$ copper grid.

Thermogravimetric analysis (TGA) was performed on a Mettler Toledo A851 TGA/SDTA instrument using the dynamic method. About $15 \mathrm{mg}$ of the sample (clay or polymer) was placed in open $150 \mu \mathrm{L}$ alumina pans. Temperature was scanned from $25^{\circ} \mathrm{C}$ to $1000{ }^{\circ} \mathrm{C}$ at a rate of $10{ }^{\circ} \mathrm{C} \min ^{-1}$ with air flowing at a rate of $50 \mathrm{~mL} \mathrm{~min}{ }^{-1}$.

Dynamic mechanical properties were recorded on a Perkin Elmer DMA 8000 instrument. Dynamic tests were performed in the single cantilever bending mode at a frequency of $100 \mathrm{~Hz}$ and a displacement of $0.05 \mathrm{~mm}$. Sample lengths, widths and thicknesses were about $17.30 \mathrm{~mm}, 4.40 \mathrm{~mm}$ and $2.60 \mathrm{~mm}$ respectively. Temperature was scanned from $-40{ }^{\circ} \mathrm{C}$ to $100{ }^{\circ} \mathrm{C}$ at a scan rate of $1^{\circ} \mathrm{C} \mathrm{min}^{-1}$.

Melt viscosities were determined at $160{ }^{\circ} \mathrm{C}$ in the steady shear, rotational mode. An Anton Paar Physica MCR301 rheometer with a CTD 600a convection hood and fitted with a 
$50 \mathrm{~mm}$ cone-and-plate measuring system was used. The gap was set at $51 \mu \mathrm{m}$ and the shear rate was varied from $0.1 \mathrm{~s}^{-1}$ to $40 \mathrm{~s}^{-1}$.

\section{Results}

Clay characterization

The XRF-determined chemical compositions of the clay samples are presented in Table 1. Both samples exhibited a high silica content that is attributed to the presence of ca. $35.7 \mathrm{wt} . \%$ crystobalite as a major impurity [22]. The ammonium-modified bentonite showed a significant reduction in the sodium $(2.11 \%)$ and calcium $(0.39 \%)$ levels (described in terms of $\mathrm{Na}_{2} \mathrm{O}$ and $\mathrm{CaO}$ respectively). This confirmed the successful ion exchange of these exchangeable inorganic cations with ammonium ions.

Fig. 2 shows the XRD patterns of the pristine clay (MMT) and the modified clay $\left(\mathrm{NH}_{4}{ }^{+}-\mathrm{MMT}\right)$. The pristine clay showed a strong reflection at $2 \theta=8.164^{\circ}$, corresponding to a basal spacing of $1.257 \mathrm{~nm}$ of the (001) planes. In the $\mathrm{NH}_{4}{ }^{+}-\mathrm{MMT}$ the (001) plane reflection shifted to $7.144^{\circ}$, corresponding to a basal spacing of $1.437 \mathrm{~nm}$. This slight increase in the interlayer spacing of the modified sample suggests that the ammonium ion treatment conferred an effect on the clay.

The TGA results shown in Fig. 3 indicate that mass loss proceeded stepwise in all samples. The neat MMT sample showed a higher mass loss compared to the $\mathrm{NH}_{4}{ }^{+}$-MMT sample. The DTA signal (not shown) indicated endothermic peaks just below $100{ }^{\circ} \mathrm{C}$ for both samples that were attributed to the loss of interlayer water. The endothermic peak was more intense in the neat clay suggesting that the water content was higher. This was expected as the $\mathrm{Ca}^{2+}$ and $\mathrm{Na}^{+}$ions have a stronger tendency for hydration than the $\mathrm{NH}_{4}{ }^{+}$ion. 


\section{Composites characterization}

Mass loss curves vs. temperature of neat polyamide (as received but dried at $60{ }^{\circ} \mathrm{C}$ for $24 \mathrm{~h}$ ) and its clay composites are shown in Fig. 4. The actual clay content levels of the bionanocomposites were determined from the relative mass loss values measured at $1000{ }^{\circ} \mathrm{C}$ for the modified clay and the bio-nanocomposites.

The mass loss up to $150{ }^{\circ} \mathrm{C}$ is often associated with the moisture content of polyamides. This value was $0.15 \mathrm{wt} . \%$ for the neat polymer and less than this for the composites. Up to $320^{\circ} \mathrm{C}$, the measured mass loss values for the clay composites were lower than that of the neat polyamide i.e. $2.7 \mathrm{wt} . \%$. In addition they followed a similar trend in this temperature range. These observations indicate that the composites were free of residual acetic acid.

Only two major thermal events were observed in the TGA curves of the composites and the neat polyamide. The first stage of degradation involved major mass loss, commencing at $398{ }^{\circ} \mathrm{C}, 408{ }^{\circ} \mathrm{C}, 411^{\circ} \mathrm{C}$ and $420{ }^{\circ} \mathrm{C}$ for neat polymer and the composites with clay content of 7.9, 14.6 and 27.5 wt.\%, respectively. Fig. 4 also shows that the composite samples were more stable than the neat polyamide under thermo-oxidative degradation conditions. Above $350{ }^{\circ} \mathrm{C}$, the neat polymer showed rapid mass loss, leaving a $10.5 \mathrm{wt} . \%$ residue at $483{ }^{\circ} \mathrm{C}$. This was completely oxidized to volatile products between $520{ }^{\circ} \mathrm{C}$ and $1000{ }^{\circ} \mathrm{C}$. Between $350{ }^{\circ} \mathrm{C}$ and $600{ }^{\circ} \mathrm{C}$ the residues of the polymer composites were higher than that observed for the neat polyamide. The presence of clay apparently enhanced thermal stability. This can be attributed to barrier effects preventing oxygen diffusion into the matrix and the release to the atmosphere of small molecule fragments generated during the thermal decomposition process [23]. In addition, it is clear from Fig. 4 that the degradation onset temperature was slightly higher for the clay composites. The DTG peaks (not presented here) 
indicate the temperature corresponding to the maximum degradation. These occurred at about the same temperature for the neat polymer and its composites, i.e. $463{ }^{\circ} \mathrm{C}$.

The XRD diffractograms of the polyamide- $\mathrm{NH}_{4}{ }^{+}$-MMT composites, shown in Fig. 5, featured poorly defined reflections. The (001) plane reflections were broader and less intense but were located at approximately the same angle as for the $\mathrm{NH}_{4}{ }^{+}-\mathrm{MMT}$ clay. The lower intensity is consistent with a certain degree of disorder or even some clay exfoliation. Nevertheless, the presence of (001) reflections are indicative of the retention of neat $\mathrm{NH}_{4}{ }^{+}-$ MMT clay structure rather than the formation of intercalated microstructures [24]. Intercalated structures form when the protonated polymer chains enter into the clay galleries causing expansions of up to $3 \mathrm{~nm}$. Thus intercalated structures form a more or less ordered multilayer structure of alternating polymeric and inorganic layers [17]. The present XRD patterns are not consistent with such a situation as the reflections did not shift to lower angles.

The SEM micrographs in Fig. 6 revealed significant changes in the morphologies of the fracture surfaces as the clay content increased [25]. Distinct clay agglomerates were not visible in the SEM, even at high magnification. However, dispersed clay tactoids were observed in all the clay-containing samples. These results indicate that the processing conditions were not effective enough to facilitate complete exfoliation or even intercalation of the clay particles. The fracture surface of the neat polyamide (not shown) was relatively smooth. Those for the bio-nanocomposites had a rough surface appearance. The roughness increased with clay content similar to previous observations [26]. Fig. 6 also shows the outside surface texture of the sheet prepared using the composite containing $27.5 \%$ clay.

Transmission electron micrographs (TEM) can provide quantitative information on the morphology and internal structure of a nanocomposite including clay platelet separation, 
etc. $[27,24]$. Illustrative TEM results for the present bio-nanocomposites are shown in Fig. 7. The dark lines represent delaminated clay layers dispersed in the polymer matrix. The bionanocomposite with 7.9 wt.\% clay showed a significant number of individual exfoliated clay sheets dispersed together with thicker tactoids. In the bio-nanocomposite with 27.5 wt.\% clay fewer exfoliated platelets were visible in the bulk and more clay tactoids was observed. Thus, as the clay content increased, the degree of dispersion decreased and the clay was present primarily as tactoids. A similar result was previously reported by Anilkumar et al. [28] High particle aspect ratios are key for increasing the moduli of filled polymer composites [29]. The TEM micrographs show that even the tactoids featured very high aspect ratio's as their thickness corresponded to a few nanometers while their lengths reached $1 \mu \mathrm{m}$.

Fig. 8 reveals the effect of the clay on the loss factor $(\tan \delta)$ for the composites. The $T g$ values were associated with the peak temperatures of the $\tan \delta$-temperature curves. At a frequency of $100 \mathrm{~Hz}$, the $\mathrm{Tg}$ shifted from $9.8^{\circ} \mathrm{C}$ for the neat polymer, to $14.5^{\circ} \mathrm{C}, 16.0^{\circ} \mathrm{C}$ and $20.2{ }^{\circ} \mathrm{C}$ for composites with clay contents of $7.9 \mathrm{wt} . \%, 14.6 \mathrm{wt} . \%$ and $27.5 \mathrm{wt} . \%$ respectively. In addition, the $\tan \delta$ peaks became broader and weaker as the clay content increased. These increases in the apparent glass transition temperature $(T g)$ indicate that the presence of the clay significantly affected the mobility of the polyamide chain segments.

Fig. 9 shows the temperature dependence of the storage modulus $\left(E^{\prime}\right)$ at $100 \mathrm{~Hz}$ for the neat polyamide and its composites. All the compounds exhibited similar trends with the storage modulus decreasing with increasing temperature. This behaviour can be attributed to the increase in segmental polymer chain motions with temperature as the thermal energy overcomes the inter-chain hydrogen bonding interactions along the polyamide chains. As expected, the storage modulus values for the composites are higher than that of the neat polyamide in the range of evaluated temperatures. The upward shift indicates that the 
incorporation of clay remarkably enhanced stiffness providing a good reinforcing effect. The $E^{\prime}$ values for the composites improved as the clay content increased. At $-30{ }^{\circ} \mathrm{C}$, i. e. well below the glass transition temperature $(\mathrm{Tg})$ of the neat polyamide $\left(\mathrm{Tg}=10{ }^{\circ} \mathrm{C}\right.$, refer to Fig. 8) the storage modulus values of the composites with clay contents of 7.9, 14.6 and $27.5 \mathrm{wt} . \%$ were respectively $1.23(6.27 \mathrm{GPa}), 1.74(8.92 \mathrm{GPa})$ and $2.5(12.8 \mathrm{GPa})$ times higher than that of pure polyamide $(5.12 \mathrm{GPa})$. At $70{ }^{\circ} \mathrm{C}$ the corresponding ratio's and modulus values were $1.99(69 \mathrm{MPa}), 4.97(172 \mathrm{MPa})$ and $9.1(315 \mathrm{MPa})$ respectively, with the modulus value for the neat polyamide equal to $35 \mathrm{MPa}$. These values and Fig. 9 in general show that the stiffness enhancement was less pronounced at temperatures below $T g$. This behaviour is related to the fact that, below $T g$, the polymer is in a glassy state where segmental chain motions are frozen. However, above $T g$, when the matrix polymer has a lower stiffness, the reinforcement effect of the clay particles was more prominent. This is attributed to the high surface area of the rigid clay that hampers segmental motions of adjacent polymer chains. This mechanism was previously used to explain the reinforcing action of rigid fillers with high moduli such as layered silicates [24]. The observed shift in the glass transition temperature, as the clay content is increased (Fig. 8), supports this contention.

The rheological behaviour of molten bio-nanocomposites complements XRD and TEM information on the degree of exfoliation of clay platelets in a polymer matrix [30]. Fig. 10 shows the effect of clay content and shear rate on the melt viscosity of polyamide-clay composites. The high viscosity at low shear rates points to strong interactions between the delaminated clay platelets and the polymer chains or, alternatively, the formation of network structures by clay particle interactions. Pronounced shear thinning indicates extensive clay exfoliation in a given system [30-32]. The nanocomposites internal structure is retained at low shear rates but at high shear rates the clay network structures break down and the 
platelets tend to orient in the flow direction. The resulting platelet alignment decreases the apparent viscosity so that it approaches that of the neat polymer melt $[32,31]$. This ability to re-orient the silicates layers or tactoids in response to externally applied flows also controls the viscoelastic properties of the composites [33].

\section{Discussion}

The present data are consistent with a mixed microstructure of exfoliated clay sheets and tactoids with a thickness of less than $50 \mathrm{~nm}$. These thickness dimensions are most likely determined by the conditions the clay experienced in the acetic acid dispersion. According to Yariv and Cross [34], clay tactoids may be regarded as associated colloids. The number of associated sheets present in the clay dispersion is determined by the balance between entropic effects that direct for complete exfoliation and electrostatic forces that direct for larger tactoids. Even in water medium, $\mathrm{NH}_{4}{ }^{+}$-MMT forms tactoids comprising several unit layers $[35,36]$. Much larger tactoids are expected in acetic acid medium as it has a lower dielectric constant than water. Thus it is likely that the protonated amine end groups on the polyamide chains only displaced the surface charges on the clay tactoids present in the acetic acid dispersion. This is supported by the fact that no evidence of polymer intercalation was found in the present study.

\section{Conclusions}

Clay bio-nanocomposites, based on a dimer fatty acid-based polyamide, were successfully prepared from ammonium ion-exchanged montmorrilonite clay. This new method did not employ any surfactants. The composites were made by mixing an acetic acid dispersion of partially delaminated clay particles with a solution of the polyamide in the same solvent. The 
composite was recovered via precipitation by adding water. TEM and XRD results confirmed the formation of a bio-nanocomposite with a mixed morphology containing some exfoliated clay sheets together with nano-sized clay tactoids. However, the XRD results indicate that the polymer did not intercalate into the clay galleries. This suggests that the clay morphology was fixed at the acetic acid dispersion stage. At best, the protonated amine end groups of the polymer chains only replaced the ammonium ions on the surface of the clay particles originally present in the acetic acid dispersion. This stabilized the clay platelets and compatibilised them with the polyamide matrix. Addition of $27.5 \mathrm{wt} . \%$ clay increased the modulus of the parent polymer by up to a factor of two and a half in the glassy region and by almost an order of magnitude in the rubbery region. The glass transition temperature $(\mathrm{Tg})$ of the polymer increased by about $5{ }^{\circ} \mathrm{C}$ when $27.5 \mathrm{wt} . \%$ clay was added. This indicates that the high contact surface area presented by the dispersed clay platelets dispersed in the composites inhibited segmental polymer chain mobility. This implies an effective stiffening of the polymer matrix at temperatures above $T g$. This also explains the higher apparent reinforcing effect observed at temperatures above $T g$. In conclusion, the key finding of this work is that organo-modification of clays with surfactants is not essential for the preparation of polyamide-clay nanocomposites.

\section{Acknowledgements}

Financial support for this research from the Institutional Research Development Programme (IRDP) and the South Africa/Mozambique Collaboration Programme of the National Research Foundation (NRF) is gratefully acknowledged. Dhorali Gnanasekaran acknowledges support via a Vice-Chancellor postdoc fellowship from the University of Pretoria. 


\section{References}

1. Hablot E, Donnio B, Bouquey M, Avérous L (2010) Dimer acid-based thermoplastic biopolyamides: Reaction kinetics, properties and structure. Polymer 51 (25):5895-5902

2. Montero De Espinosa L, Meier MAR (2011) Plant oils: The perfect renewable resource for polymer science?! European Polymer Journal 47 (5):837-852

3. Matadi R, Hablot E, Wang K, Bahlouli N, Ahzi S, Avérous L (2011) High strain rate behaviour of renewable biocomposites based on dimer fatty acid polyamides and cellulose fibres. Composites Science and Technology 71 (5):674-682

4. Petersson L, Oksman K (2006) Biopolymer based nanocomposites: Comparing layered silicates and microcrystalline cellulose as nanoreinforcement. Composites Science and Technology 66 (13):2187-2196

5. Satyanarayana KG, Arizaga GGC, Wypych F (2009) Biodegradable composites based on lignocellulosic fibers-An overview. Progress in Polymer Science (Oxford) 34 (9):9821021

6. Mohanty AK, Misra M, Drzal LT (2002) Sustainable Bio-Composites from renewable resources: Opportunities and challenges in the green materials world. Journal of Polymers and the Environment 10 (1-2):19-26

7. Sati N. Bhattacharya MRK, Rahul K. Gupta (2008) Polymeric Nanocomposites Theory and Practice. Hanser, Munich

8. Fu SY, Feng XQ, Lauke B, Mai YW (2008) Effects of particle size, particle/matrix interface adhesion and particle loading on mechanical properties of particulate-polymer composites. Composites Part B: Engineering 39 (6):933-961

9. Alexandre M, Dubois P (2000) Polymer-layered silicate nanocomposites: Preparation, properties and uses of a new class of materials. Materials Science and Engineering R: Reports 28 (1):1-63

10. Sur GS (2003) Synthesis and LCST Behavior of Thermosensitive Poly (TVisopropylacrylamide)-Clay Nanocomposites. Journal of Industrial and Engineering Chemistry 9 (1):58-62

11. Zhang Q, Yu M, Fu Q (2004) Crystal morphology and crystallization kinetics of polyamide-11/clay nanocomposites. Polymer International 53 (12):1941-1949

12. Kumar AP, Depan D, Singh Tomer N, Singh RP (2009) Nanoscale particles for polymer degradation and stabilization-Trends and future perspectives. Progress in Polymer Science (Oxford) 34 (6):479-515

13. Kiliaris P, Papaspyrides CD (2010) Polymer/layered silicate (clay) nanocomposites: An overview of flame retardancy. Progress in Polymer Science (Oxford) 35 (7):902-958

14. Azeredo HMCd (2009) Nanocomposites for food packaging applications. Food Research International 42 (9):1240-1253

15. Vaia RA, Giannelis EP (1997) Lattice model of polymer melt intercalation in organicallymodified layered silicates. Macromolecules 30 (25):7990-7999

16. Fischer $\mathrm{H}$ (2003) Polymer nanocomposites: From fundamental research to specific applications. Materials Science and Engineering C 23 (6-8):763-772

17. Sinha Ray S, Okamoto M (2003) Polymer/layered silicate nanocomposites: A review from preparation to processing. Progress in Polymer Science (Oxford) 28 (11):15391641

18. Turunc O, Firdaus M, Klein G, Meier MAR (2012) Fatty acid derived renewable polyamides via thiol-ene additions. Green Chemistry 14 (9):2577-2583. doi:10.1039/C2GC35982K 
19. Maisonneuve L, Lebarbe T, Grau E, Cramail H (2013) Structure-properties relationship of fatty acid-based thermoplastics as synthetic polymer mimics. Polymer Chemistry 4 (22):5472-5517. doi:10.1039/C3PY00791J

20. Hablot E, Matadi R, Ahzi S, Avérous L (2010) Renewable biocomposites of dimer fatty acid-based polyamides with cellulose fibres: Thermal, physical and mechanical properties. Composites Science and Technology 70 (3):504-509

21. Nicolosi V, Chhowalla M, Kanatzidis MG, Strano MS, Coleman JN (2013) Liquid exfoliation of layered materials. Science 340 (6139)

22. Massinga PH, Focke WW, de Vaal PL, Atanasova M (2010) Alkyl ammonium intercalation of Mozambican bentonite. Applied Clay Science 49 (3):142-148

23. Liu Z, Chen K, Yan D (2004) Nanocomposites of poly(trimethylene terephthalate) with various organoclays: Morphology, mechanical and thermal properties. Polymer Testing $23(3): 323-331$

24. Pavlidou S, Papaspyrides CD (2008) A review on polymer-layered silicate nanocomposites. Progress in Polymer Science (Oxford) 33 (12):1119-1198

25. Lee HM, Park BJ, Choi HJ, Gupta RK, Bhattachary SN (2007) Preparation and Rheological Characteristics of Ethylene-Vinyl Acetate Copolymer/Organoclay Nanocomposites. Journal of Macromolecular Science, Part B 46 (2):261-273. doi:10.1080/00222340601066956

26. Tjong SC (2006) Structural and mechanical properties of polymer nanocomposites. Materials Science and Engineering R: Reports 53 (3-4):73-197

27. Ma J, Xu J, Ren J-H, Yu Z-Z, Mai Y-W (2003) A new approach to polymer/montmorillonite nanocomposites. Polymer 44 (16):4619-4624. doi:http://dx.doi.org/10.1016/S0032-3861(03)00362-8

28. Anilkumar S, Kumaran MG, Thomas S (2008) Characterization of EVA/Clay Nanocomposite Membranes and Its Pervaporation Performance. The Journal of Physical Chemistry B 112 (13):4009-4015. doi:10.1021/jp7096444

29. Mondragón M, Hernández EM, Rivera-Armenta JL, Rodríguez-González FJ (2009) Injection molded thermoplastic starch/natural rubber/clay nanocomposites: Morphology and mechanical properties. Carbohydrate Polymers 77 (1):80-86

30. Gupta RK, Pasanovic-Zujo V, Bhattacharya SN (2005) Shear and extensional rheology of EVA/layered silicate-nanocomposites. Journal of Non-Newtonian Fluid Mechanics 128 (2-3):116-125

31. Wagener R, Reisinger TJG (2003) A rheological method to compare the degree of exfoliation of nanocomposites. Polymer 44 (24):7513-7518

32. Szép A, Szabó A, Tóth N, Anna P, Marosi G (2006) Role of montmorillonite in flame retardancy of ethylene-vinyl acetate copolymer. Polymer Degradation and Stability 91 (3):593-599. doi:http://dx.doi.org/10.1016/j.polymdegradstab.2005.02.026

33. Wang B, Wan T, Zeng W (2012) Rheological and thermal properties of polylactide/organic montmorillonite nanocomposites. Journal of Applied Polymer Science 125 (SUPPL. 2):E364-E371

34. Shmuel Yariv HC (2002) Organo-Clay Complexes and Interactions. Marcel Dekker, New York

35. Banin A, Lahav N (1968) Optical study of particle size of montmorillonite with various adsorbed cations. Nature 217 (5134):1146-1147

36. Edwards DG, Posner AM, Quirk JP (1965) Repulsion of chloride ions by negatively charged clay surfaces: Part 2. - Monovalent cation montmorillonites. Transactions of the Faraday Society 61:2816-2819 
Table 1 Chemical composition of the clay samples

\begin{tabular}{cccccccccccc}
\hline \multirow{2}{*}{ Sample } & \multicolumn{10}{c}{ Composition (wt.\%) } \\
\cline { 2 - 12 } & $\mathbf{S i O}_{\mathbf{2}}$ & $\mathbf{A l}_{\mathbf{2}} \mathbf{O}_{\mathbf{3}}$ & $\mathbf{F e}_{\mathbf{2}} \mathbf{O}_{\mathbf{3}}$ & $\mathbf{C a O}$ & $\mathbf{K}_{\mathbf{2}} \mathbf{O}$ & $\mathbf{\mathbf { N a } _ { 2 } \mathbf { O }}$ & $\mathbf{M g O}$ & $\mathbf{M n O}$ & $\mathbf{T i O}_{\mathbf{2}}$ & $\mathbf{P}_{\mathbf{2}} \mathbf{O}_{\mathbf{5}}$ & $\mathbf{L O I}$ \\
\hline Neat MMT & 77.51 & 10.60 & 2.19 & 0.45 & 0.18 & 2.19 & 2.23 & 0.01 & 0.20 & 0.018 & 4.45 \\
\hline $\mathrm{NH}_{4}{ }^{+}$-MMT & 80.51 & 10.27 & 2.10 & 0.06 & 0.19 & 0.08 & 1.74 & 0.01 & 0.21 & 0.021 & 4.82 \\
\hline
\end{tabular}
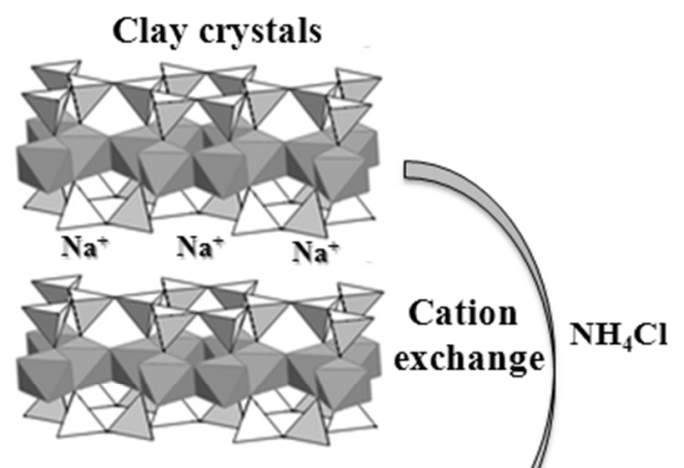

\section{Amorphous polyamide}

Clay dispersion
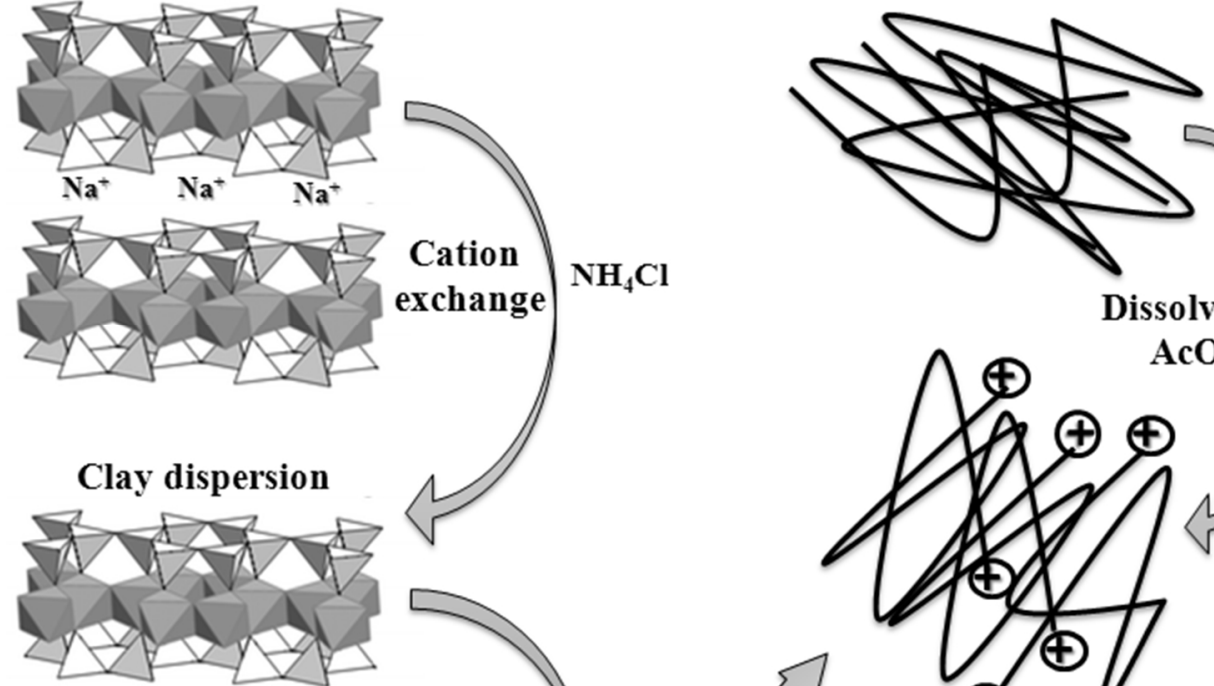

Dissolved in AcOH

$\begin{array}{lll}\mathrm{NH}_{4}{ }^{+} & \mathrm{NH}_{4}{ }^{+} & \mathrm{NH}_{4}{ }^{+}\end{array}$
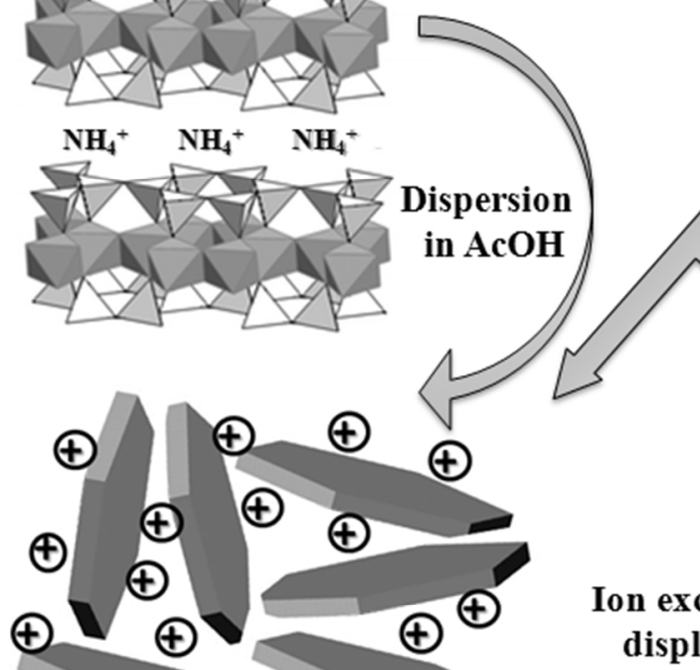

$\oplus$<smiles>[C+]</smiles><smiles>[Se]C1[C-]C[Se]1</smiles><smiles>CCCC[NH3+]</smiles>
displacing $\mathrm{NH}_{4}^{+}$

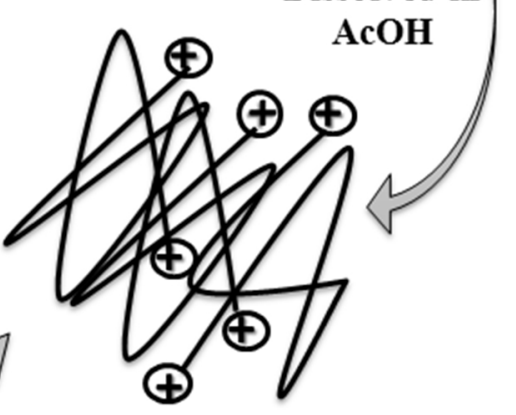

Dilute soln. of polyamide chain with protonate end groups

Partially delaminated

Clay/polyamide

$160-180^{\circ} \mathrm{C}$ composites

Precipitate with water to recover clay

Hot pressing organomodified with protonate polymers sheet

Fig. 1 Schematic representation of the route to polyamide-clay nanocomposites via solution intercalation 


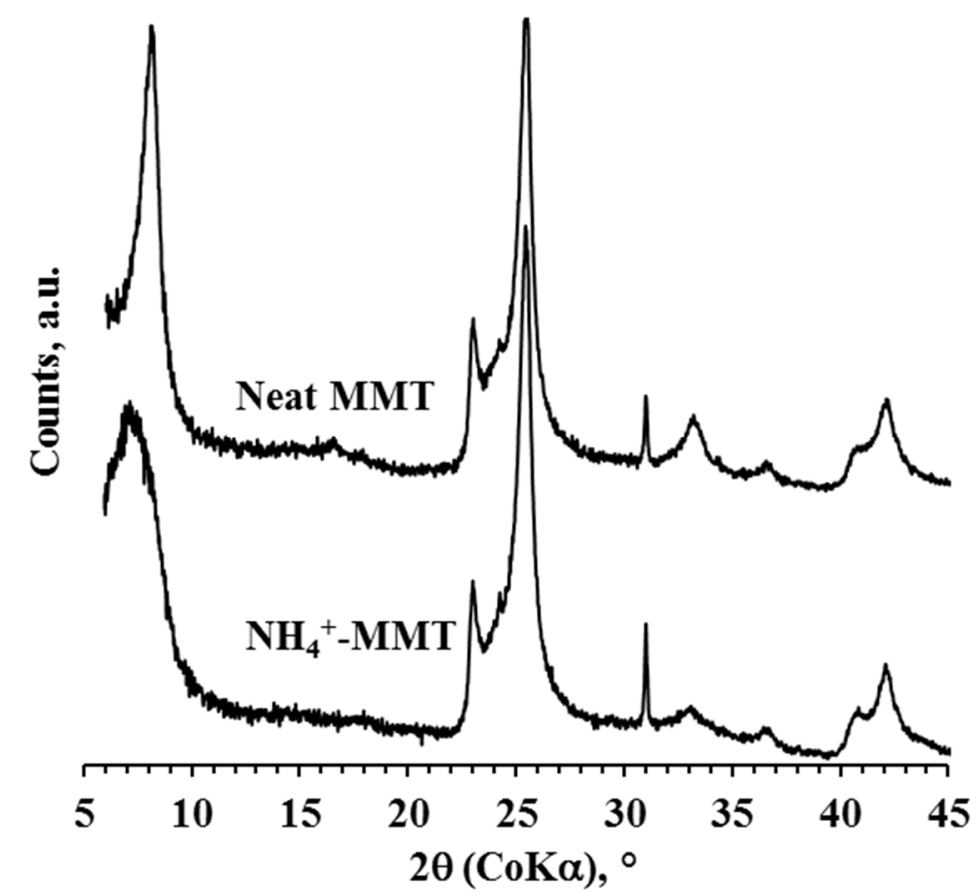

Fig. 2 XRD patterns for the neat and $\mathrm{NH}_{4}{ }^{+}$-modified clay

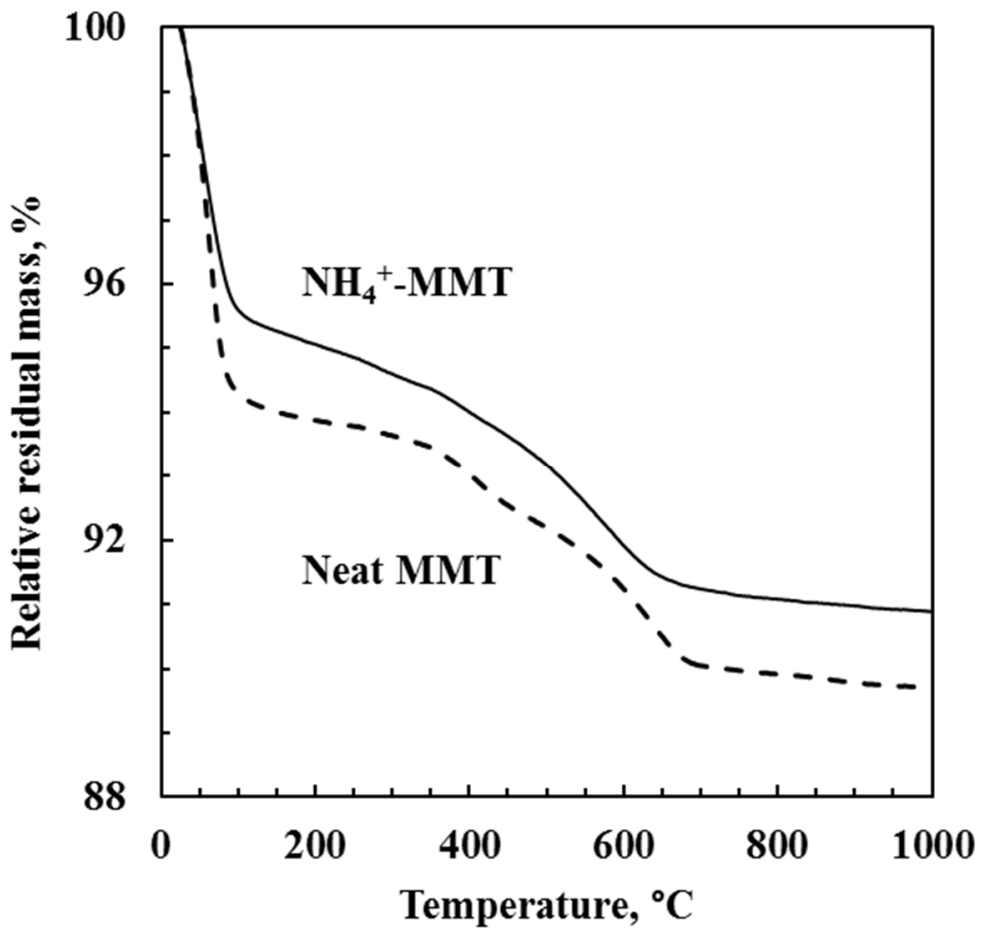

Fig. 3 TGA curves for the neat clay and $\mathrm{NH}_{4}{ }^{+}$-modified clay 


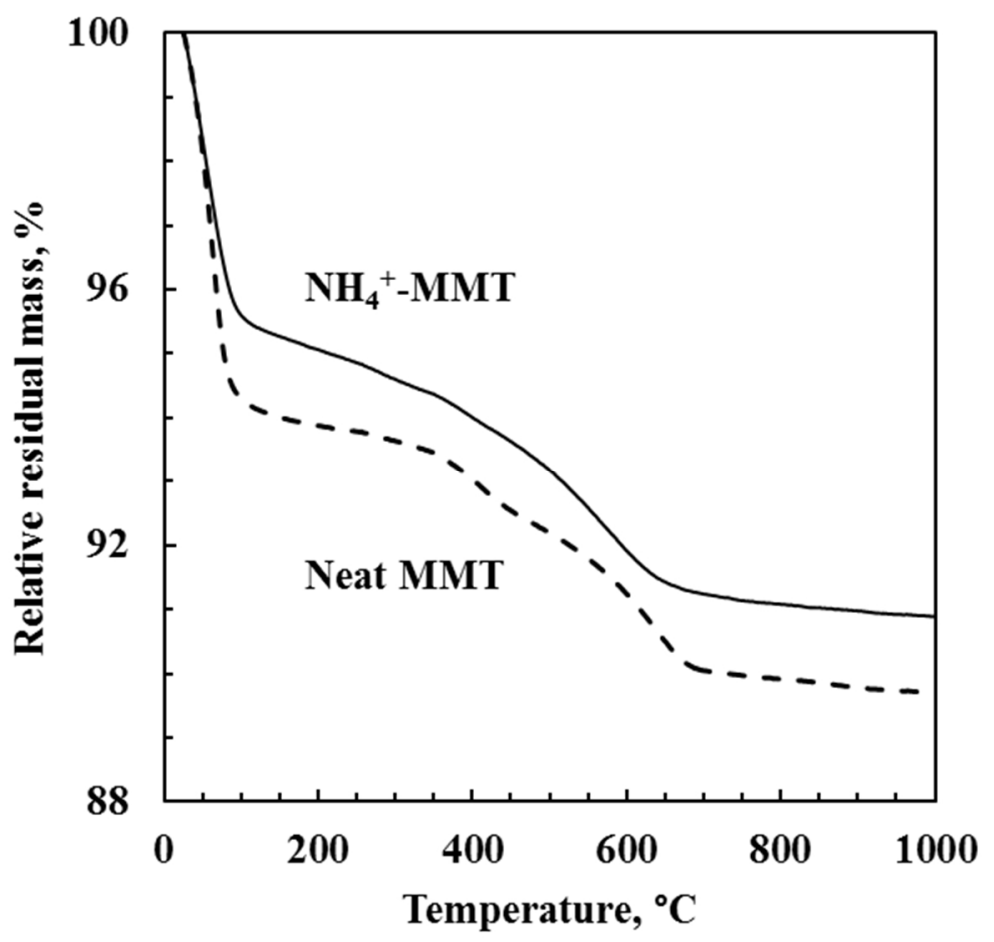

Fig. 4 TGA curves for the neat polyamide and its bio-nanocomposites

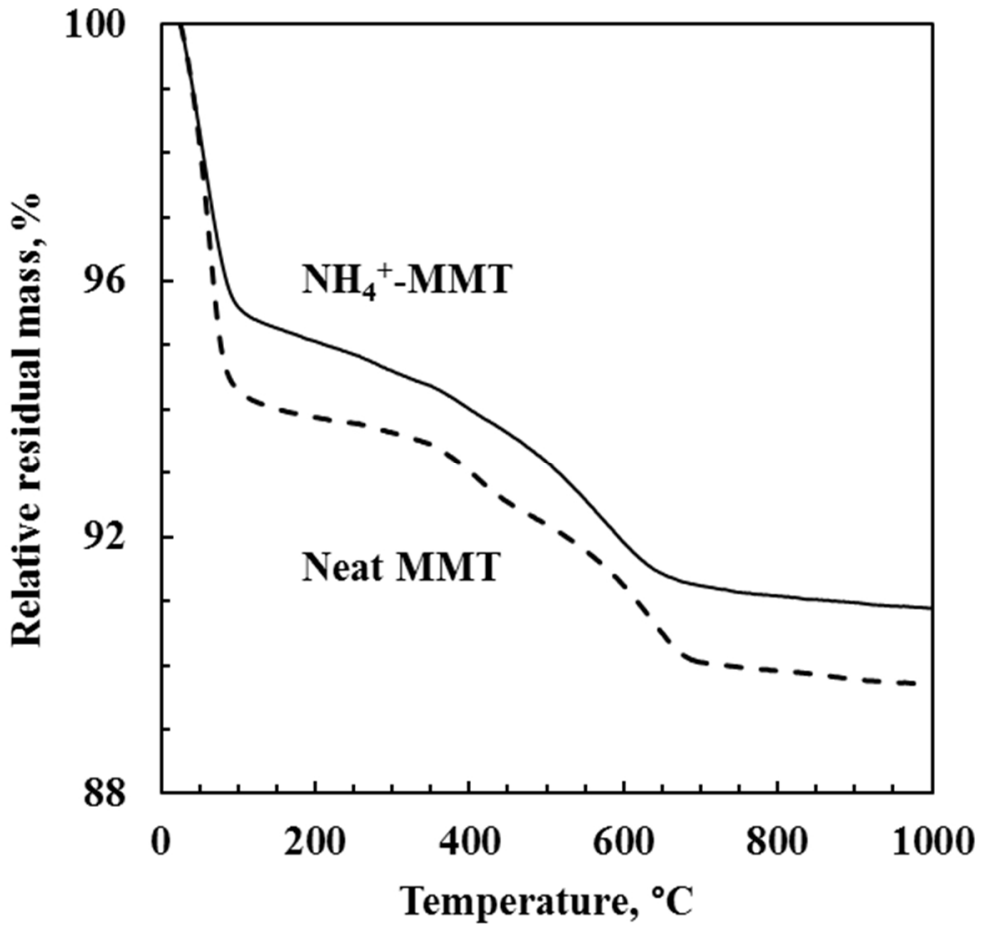

Fig. $5 \mathrm{XRD}$ patterns of the bio-nanocomposites compared to the neat $\mathrm{NH}_{4}{ }^{+}-\mathrm{MMT}$ 

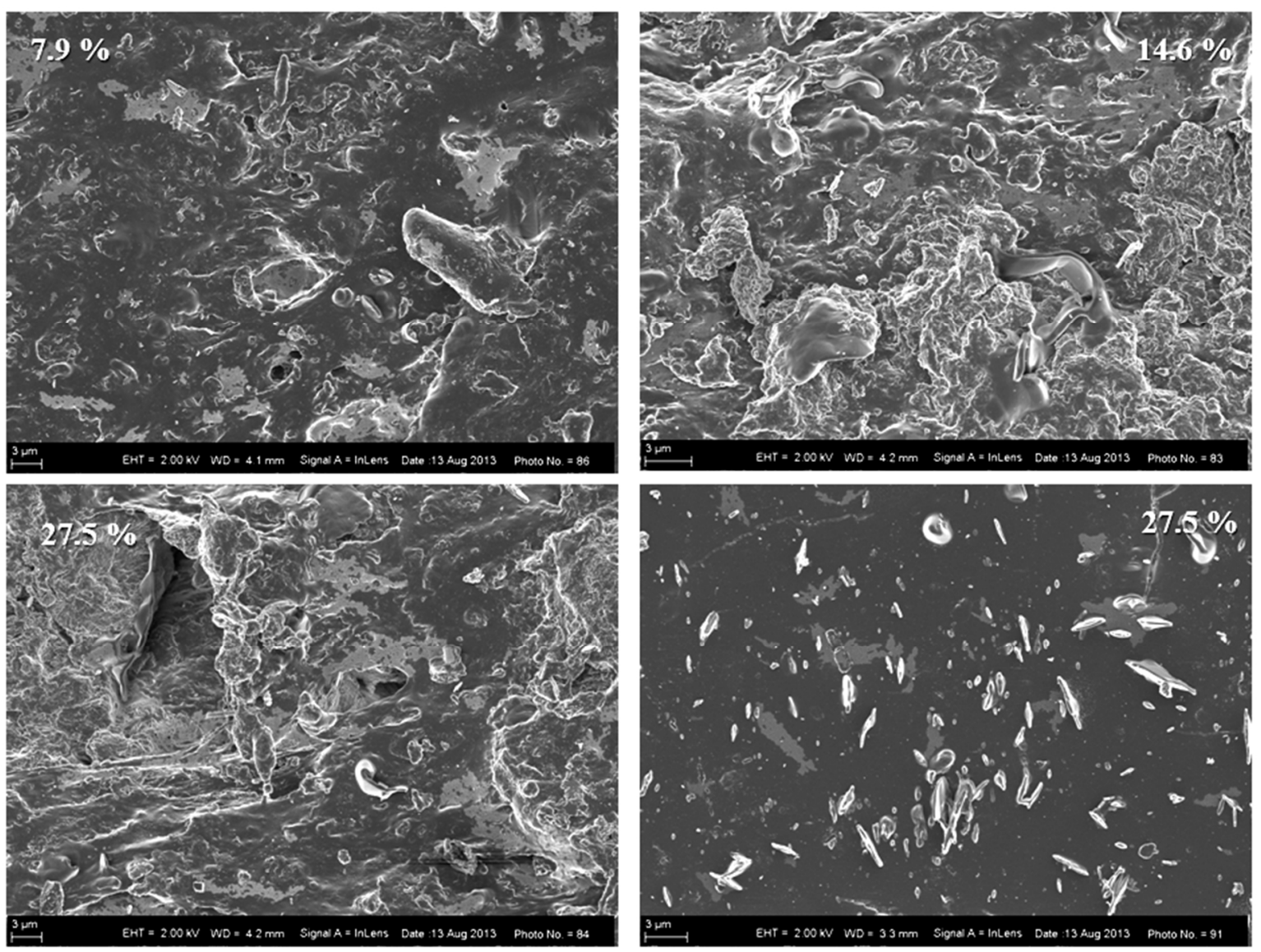

Fig. 6 SEM images of the fracture surfaces of the bio-nanocomposites with 7.9 wt.\%, 14.6

wt. $\%$ and 27.5 wt. $\%$ clay. The micrograph at the bottom right shows the surface texture of the pressed sheet for the composite containing $27.5 \mathrm{wt} . \%$ clay. 

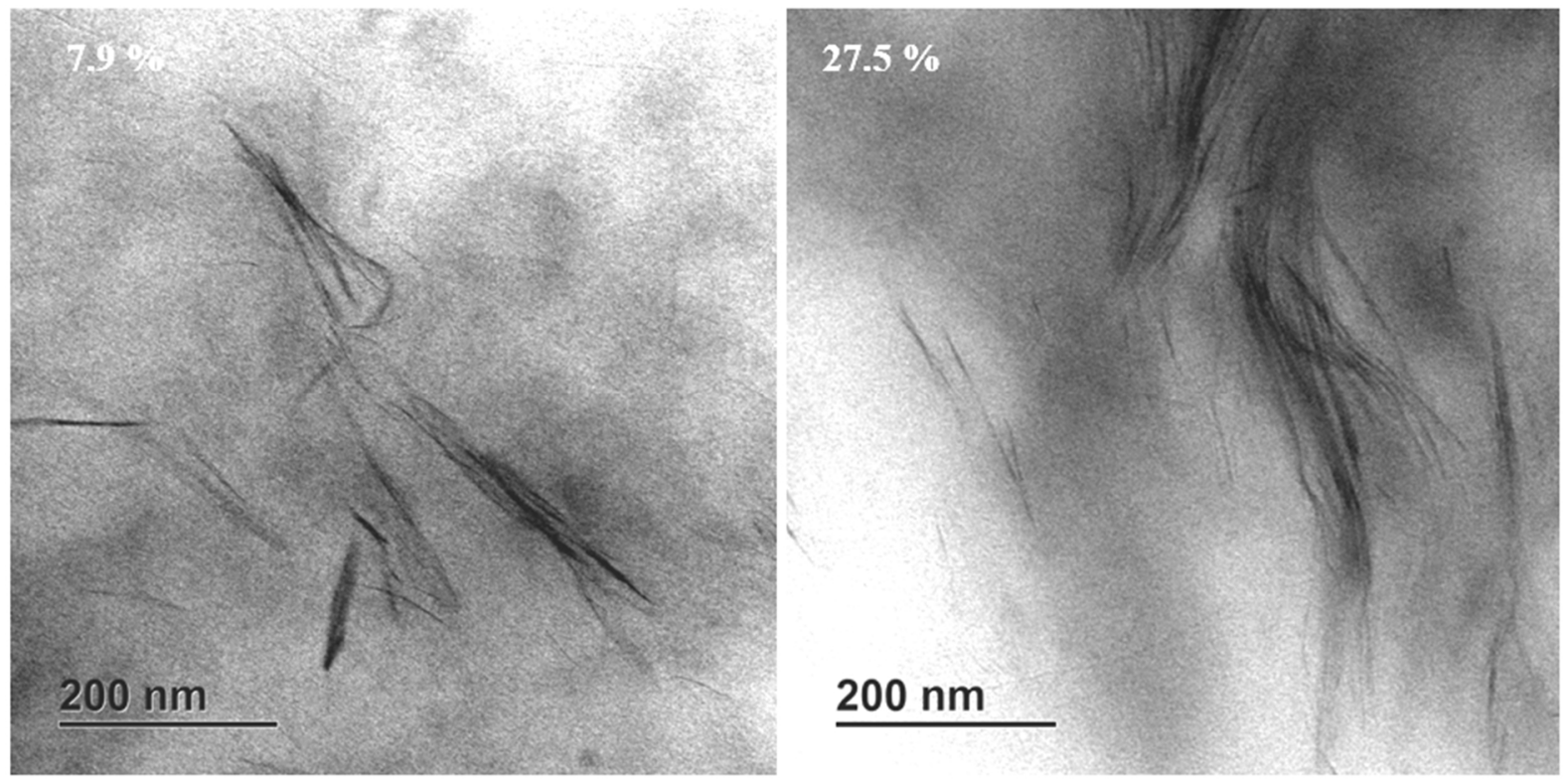

Fig. 7 TEM images of selected bio-nanocomposites

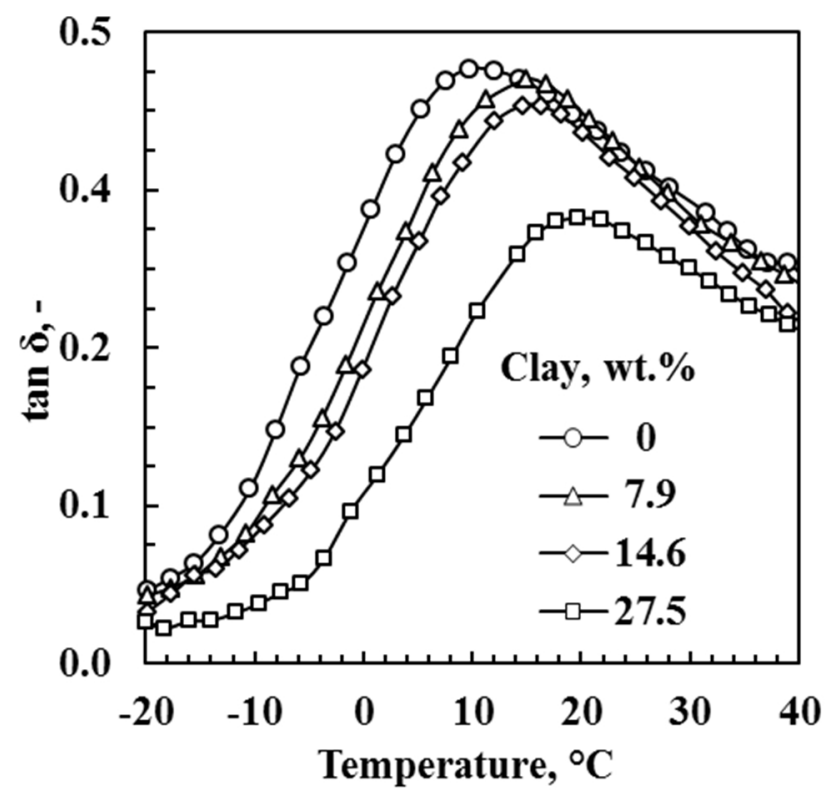

Fig. 8 Temperature dependence of $\tan \delta$ at $100 \mathrm{~Hz}$ of the polyamide and its composites 


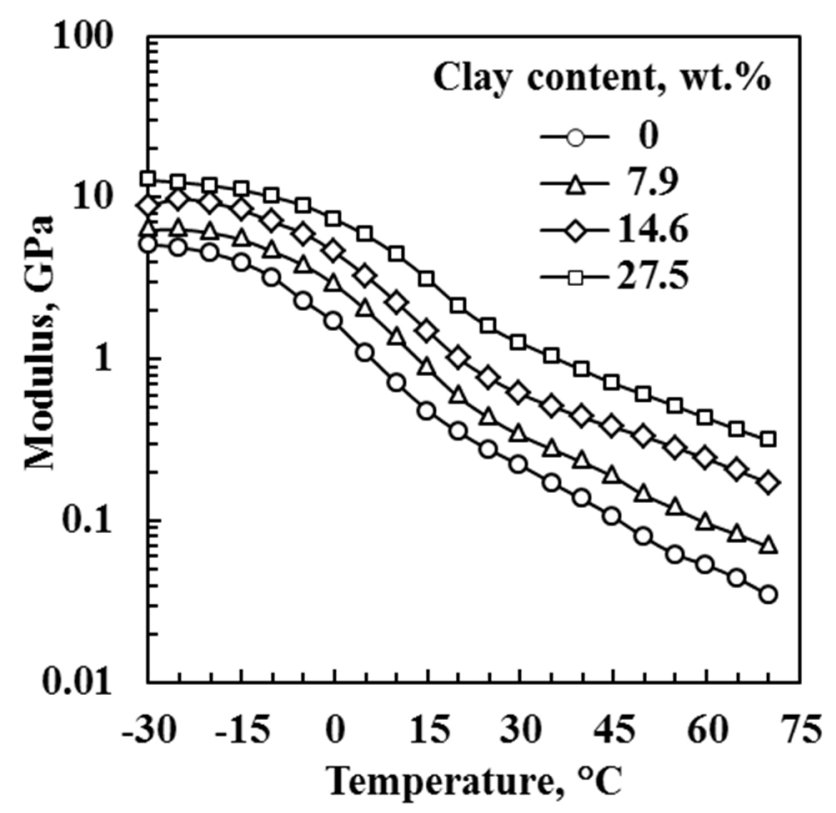

Fig. 9 Storage modulus at $100 \mathrm{~Hz}$ of the polyamide and its composites

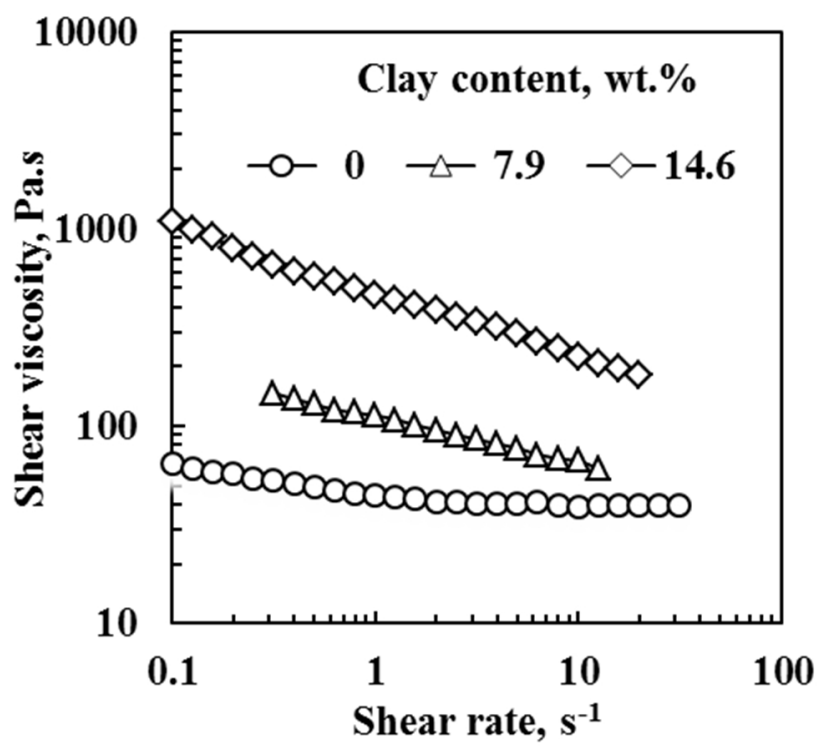

Fig. 10 Viscosity vs. shear rate for polyamide and its composite at $160{ }^{\circ} \mathrm{C}$ 